استخدام التحليل التمييزي لبيان تأثير العلاقات الاجتماعية بين ساكني

العمارات السكنية (الشقق) والدور السكنية في مدينة السليمانية

كولالة دلشاد معروف

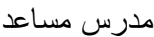

كلية الادارة و الاقتصاد -جامعة السليمانية

المستخانص

تعد العلاقات الاجتماعية بين السكان مهمة عذد التخطيط للأسدكان العدودي - الشقتى

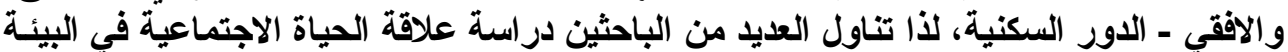
السكنيةٌ مع تخطيط و تصميم البيئة السكنية.

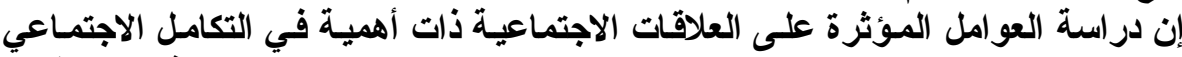

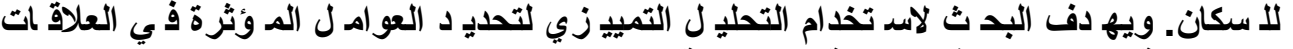
الاجتماعية بين السكان في المدينة السليمانية.

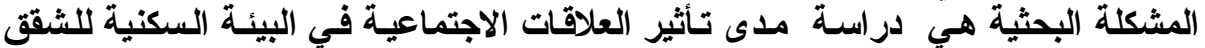

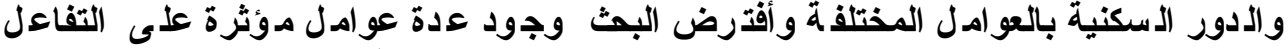

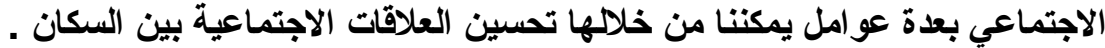

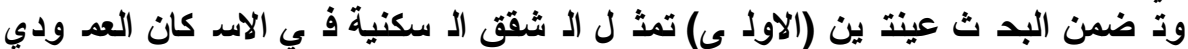

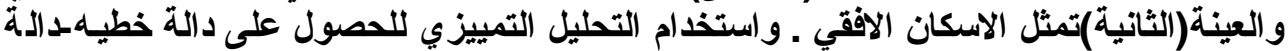
تمييزية-ويتم بها التمييز بين العينتين.

وتوصل البحث الى وجود سلسله من المتغير اتلئ تؤثر على الترابط الاجتماعي بين السكان

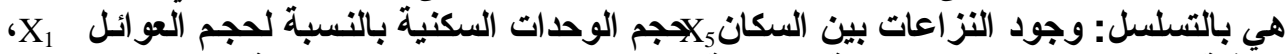

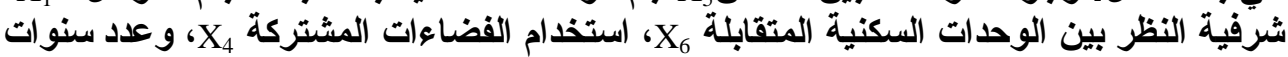

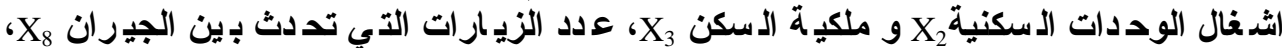
و الشرفية بين الوحدات السكنية المتجاورة 


\title{
THE USE OF DISCRIMINANT ANALYSIS TO DEFINE THE EFFECTS OF SOCIAL RELATIONSHIPS BETWEEN THE VERTICAL HOUSING (FLATS) INHABITANTS AND HOUSE INHABITANTS IN SULAYMANIA CITY
}

\author{
Gulala D. Mourof \\ Assistant Lecturer \\ Collage of Administration and Economics \\ University of Sulaymania
}

\begin{abstract}
The social relationships between inhabitants considered an important subject in housing planning - both vertical and horizontal type - in flats and houses. There are many authors studied the social relationship in residential environment with planning and designing housing. The study of factors effective on social relationship is important in social integration of residents.

The research goal: using discriminant analysis to determine factors effective on social relationship in flats and houses residents in Sulaymania. The problem of research to study the ring of social relationship effective on residents on the environment in flats and houses by different factors, the research hypothesizes that there are many factors effective of social relationship. The research studied two samples, the first sample represent flats in a vertical housing, whereas, the second sample represent houses in horizontal housing. The paper used the discriminant analysis to get out linear function - discriminant - function to discriminant between the two samples. The research results were determined many factors effected an social relationship of the residents as: The problems between residents (X5), the size of residential units according family sizes (X1), the overlook between the residential units.(X6), using green area (X4), years number using the units (X2), the units ownership (X3), the overlook between the opposite units (X6), the overlook between the other units (X7), number of visiting between residents (X8).
\end{abstract}

المقدمة

يعاثتفاعل الاجتماعي بين السكان من المو اضي ع المهمة التي ينبغي مر اعاتها

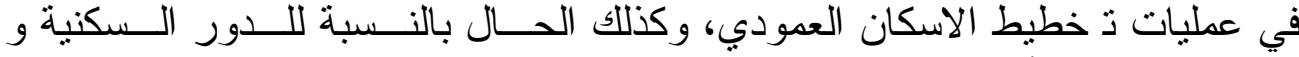

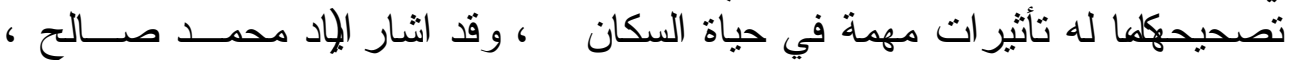

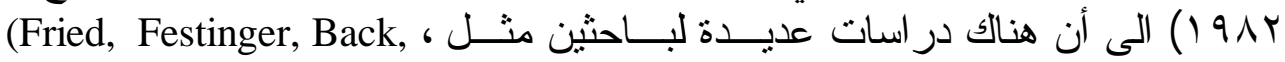
Rainwater)

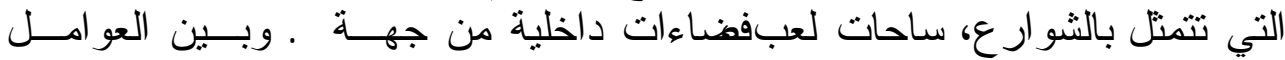

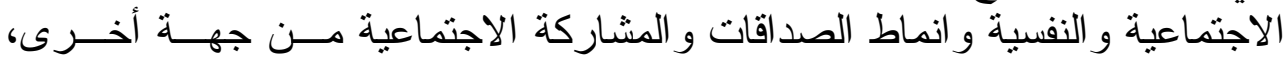

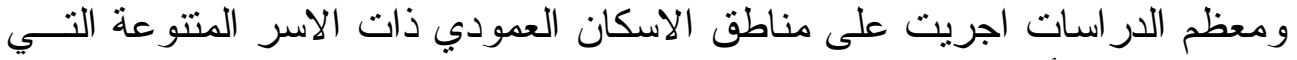

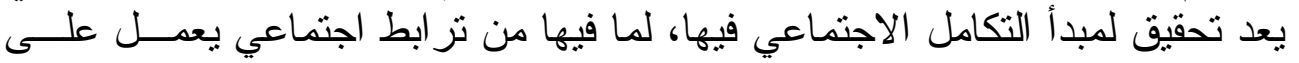
التقليل من الخلافات و التونز ات بين السكان. 
يهدف البحث الى استخدام التحليل التمبيزي لنتخيص العو امل المــؤثرة مــن التهن

\section{هدف البحث}

حيث العلاقات الاجتماعية على ساكني العمار ات السكن ية و الدور السكنية في مدينــة

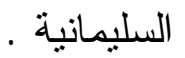

\section{Discriminante Analysis}

التحليل التمييزي

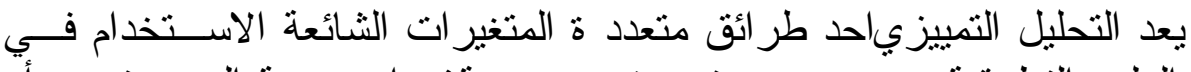

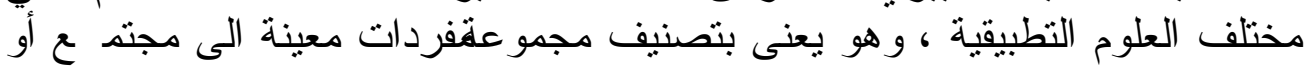

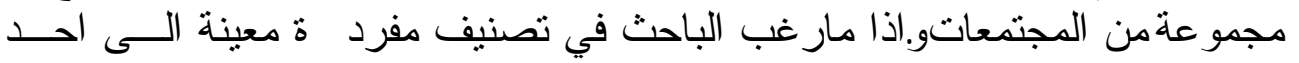

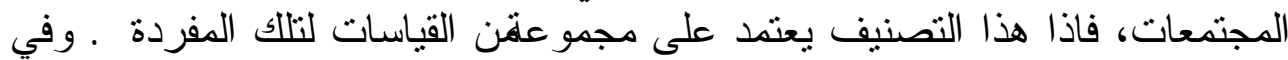

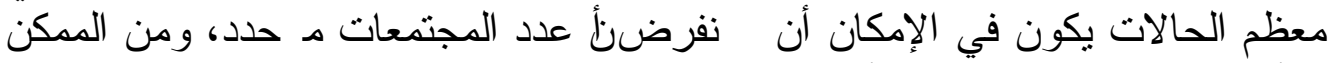

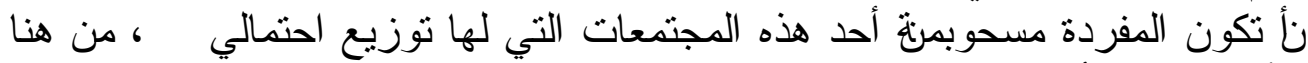
فأننا نسنطيع أن نعد المفردة عبارة عن مشاهدة عشو ائية. (Anderson,1984)

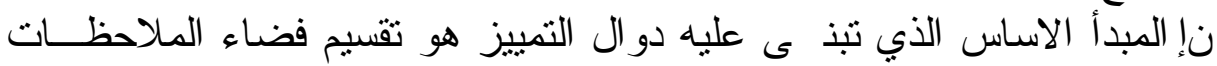

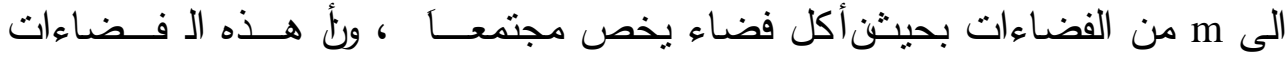

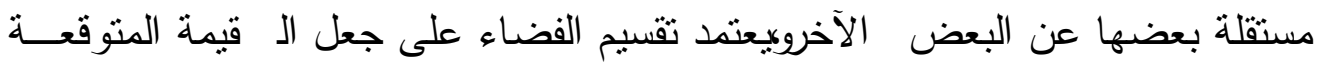

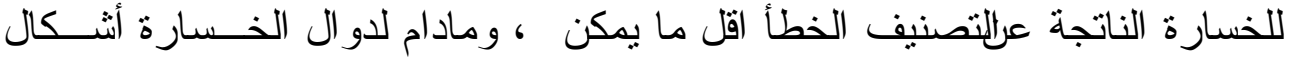

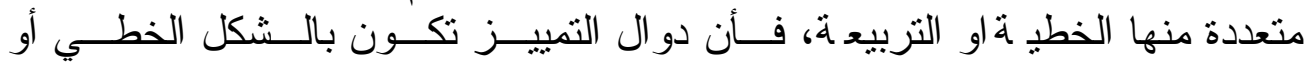

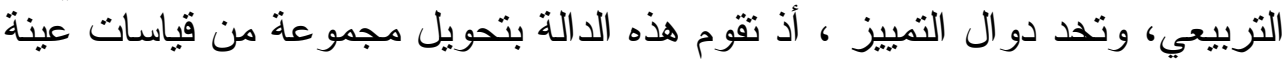

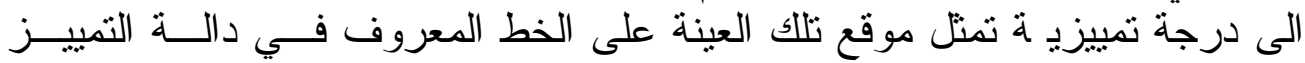

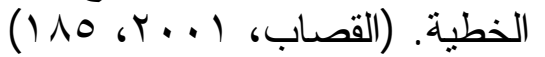

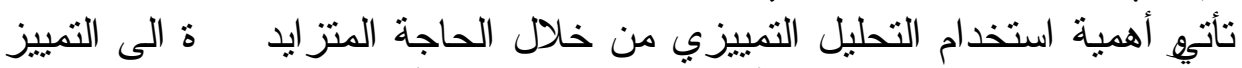

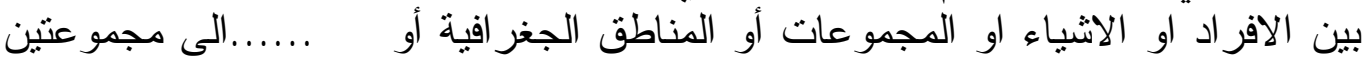

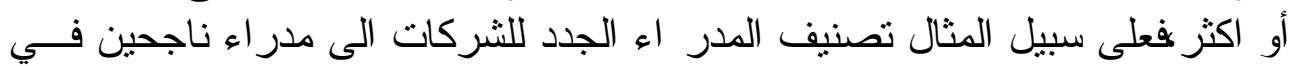

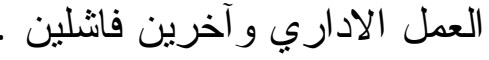

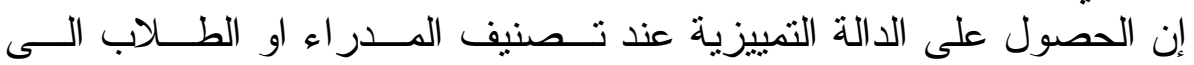

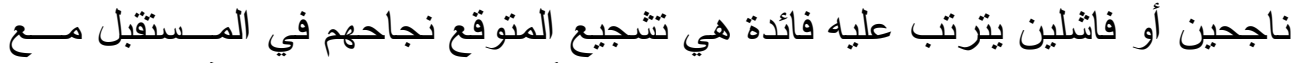

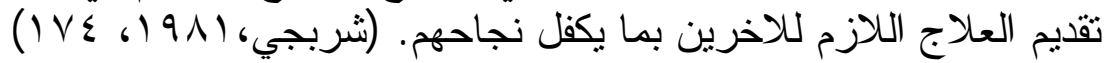

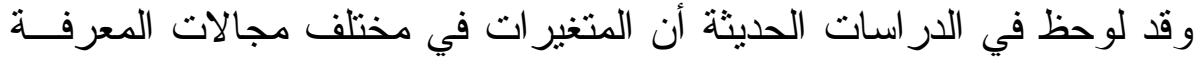

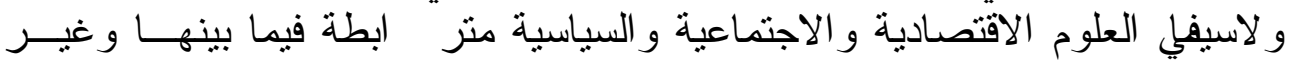

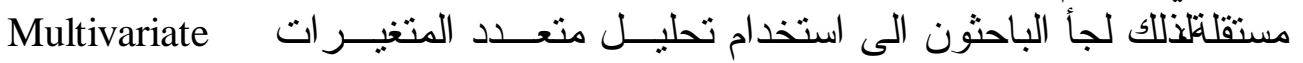

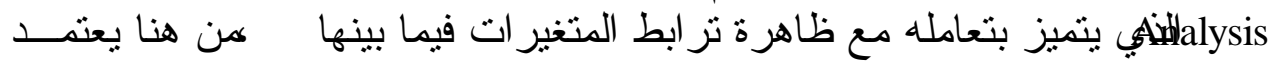

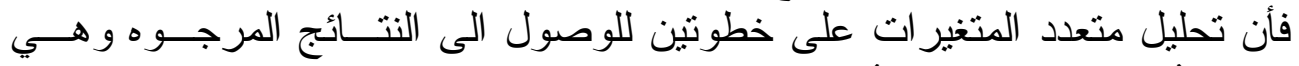

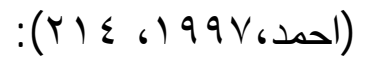
أ. تخفيض عدد المتغير ات الى أقل قدر ممكن . 


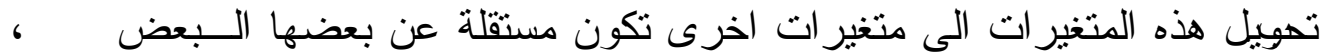

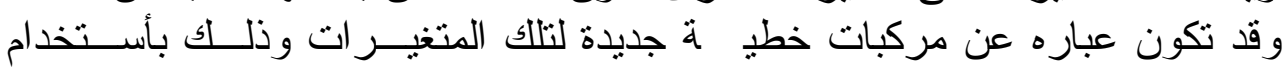

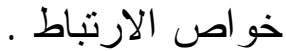

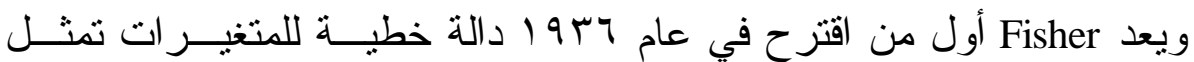

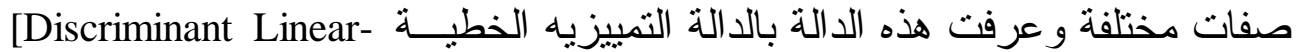
(Giri,1977, 241). Funtion]

\section{خطوات بناء الالاتة التمييزية}

لنفترض أن لدينا عينتين بحجم n n 1 n 2 مسحوبتين من مجمعتين طبيعييـين،

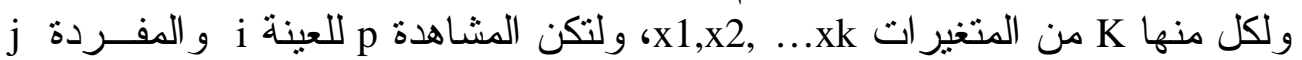

$$
\begin{aligned}
& \text { أذ } \\
& \bar{X} p i=\sum_{j=1}^{n_{i}} x \text { pij / ni }
\end{aligned}
$$

و التباين المشترك للعينة ما بين المتغير p و المتغير q في العينة i، يتمنل بـ

$$
\text { Spqi }=\sum_{j=1}(\text { Xpij }-\overline{X p i})(X q i j-\overline{X q i}) / n i
$$

$$
\mathrm{dp}=\overline{\mathrm{X}} \mathrm{p}_{1}-\overline{\mathrm{X}} \mathrm{p}_{2}
$$

و الفرق بين متوسطي العينتين للتغير p يساوي

أما التباين المشترك العام ما بين المتغيرات q و p من العينتين فهو :

$$
\mathrm{Spq}=\sum_{\mathrm{i}=1}^{2}(\mathrm{ni}-\mathrm{I}) \mathrm{Spqi} / \sum_{\mathrm{i}=1}^{2}(\mathrm{ni}-\mathrm{I})
$$

فأذا كان لدينا مجموعة من المتغير ات x1,x2,....,xk يمكن بوساطتها يمكـنـ التمييز بين مجمو عتين من المشاهدات ولتكن المعادلة الاتية:

$$
Z=a_{1} x_{1}+a_{2} x_{2}+\ldots \ldots+a_{k} x_{k}
$$

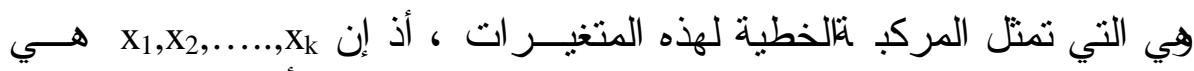

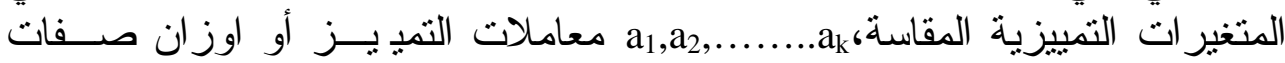

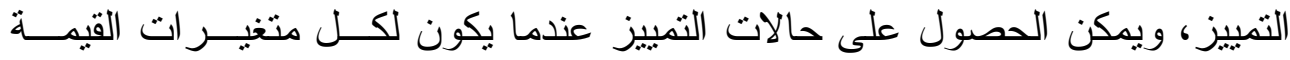
التمييزية ذاتها أب إن ولميز 
وذلك لان عددا من المتغير ات ذات اوزان تمبزيد ة اكبرمن المتغير ات الاخرى ، مما

يجعل من امر وزنها موضون عأ ذا أهمية كبيرة (Camphell,norma,1980).

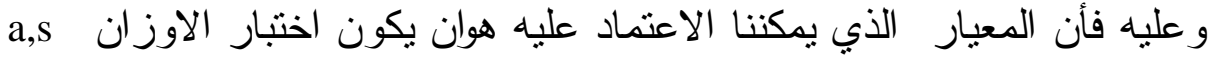

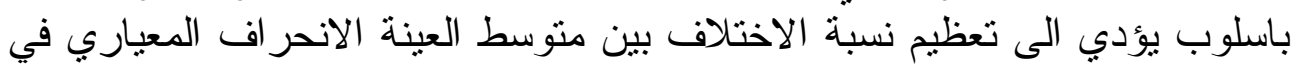

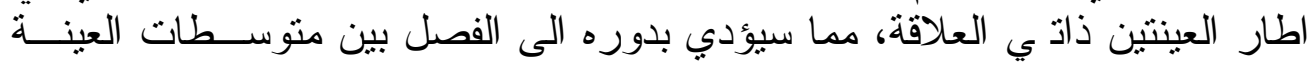

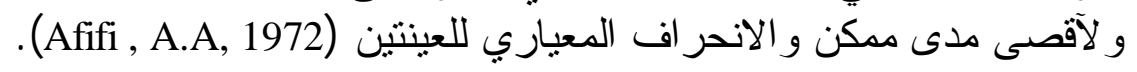

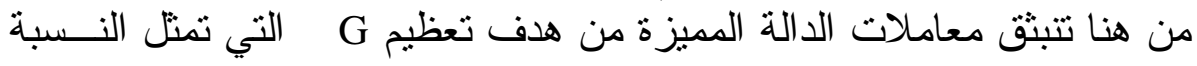

$$
\begin{aligned}
& G=\frac{\left(\bar{Z}_{1}-\bar{Z}_{2}\right)^{2}}{\sum_{i=1}^{2} \sum_{j=1}^{n}\left(Z_{i j}-\bar{Z}_{i}\right)^{2}} \\
& \text { اذ ان } \\
& \overline{\mathrm{Z}}_{1}=\mathrm{a}_{1} \overline{\mathrm{X}}_{1}\left({ }_{1}\right)+\mathrm{a}_{2} \overline{\mathrm{X}}_{2}\left({ }_{1}\right)+\ldots \ldots \ldots+\mathrm{a}_{\mathrm{k}} \overline{\mathrm{X}}_{\mathrm{k}}(1) \\
& \bar{Z}_{2}=a_{1} \bar{X}_{1}{ }^{(2)}+a_{2} \bar{X}_{2}\left({ }^{2}\right)+\ldots \ldots \ldots \ldots+a_{k} \bar{X}_{k}\left({ }^{2}\right)
\end{aligned}
$$

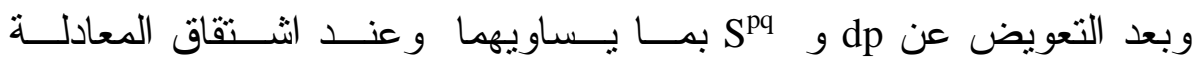

$$
\text { و مساو اتها بالصفر بنتج لدينا : }
$$
الاتية :

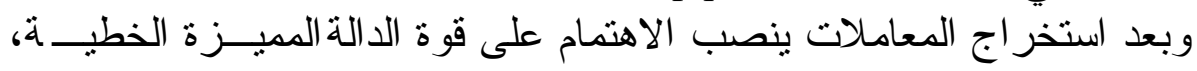

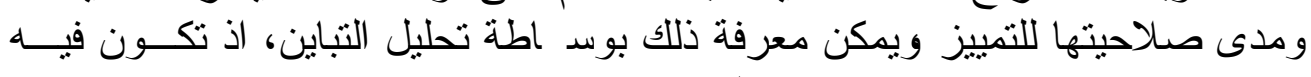

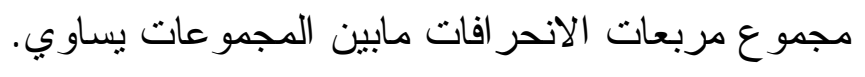

$$
\begin{aligned}
& \text { Between S.S }=\frac{\mathrm{n}_{1} \mathrm{n}_{2}}{\mathrm{n}_{1}+\mathrm{n}_{2}}\left[\mathrm{D}^{2}\right]
\end{aligned}
$$

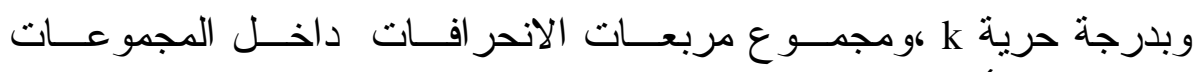

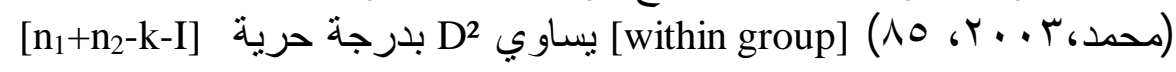

$$
\begin{aligned}
& \left.\mathrm{D}^{2}=\overline{\bar{X}}\left({ }_{1}\right)-\overline{\mathrm{X}}(2)\right)^{\prime} \mathrm{S}^{-1}(\overline{\mathrm{X}}(1)-\overline{\mathrm{X}}(2)) \\
& \text { بحيث ان : محثد : }
\end{aligned}
$$$$
\text { Spq هو معكوس المصفوفة s }
$$ 


$$
\mathrm{F}=\frac{\left(\frac{\mathrm{n}_{1} \mathrm{n}_{2}}{\mathrm{n}_{1}+\mathrm{n}_{2}}\right)\left[\mathrm{D}^{2}\right]^{2 / \mathrm{k}}}{\mathrm{D}^{2} / \mathrm{n}_{1}+\mathrm{n}_{2}-\mathrm{k}-\mathrm{I}}
$$

لذا فأن

فأذا كانت F معنوية فذلك يعني أن الدالة صـــالحة للتمييـز و وان المتغيـر ات المستخدمة تعطي احسن تمييز مابين المجمو عتين . (Overall,1972 , 251) .

بعد اثتقاق الدالة المميزة يمكن الحصول على قيمتها المفردة الجديــدة عــن

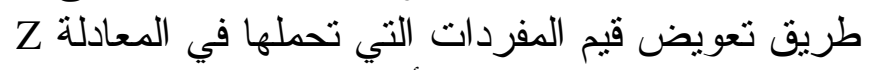
انيتم معرفة عائدية ة أية مفردة جديدة بمقارنة الدالة المميزة لها لهابة بقيمة محددة

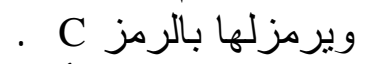

فلو فرضنا أنتا قسمنا عينة معينة الى مجمو عتين سذ طبق ما ورد سابقا بـأن

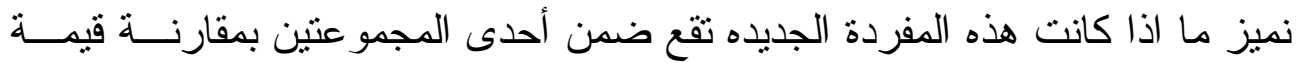

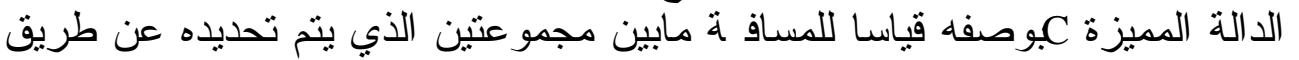

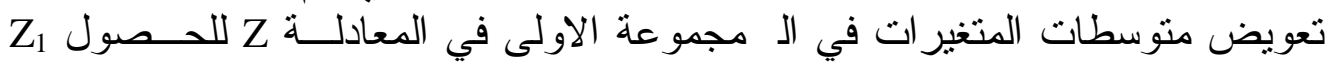

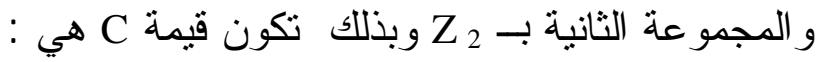

$$
\mathrm{C}=\frac{\overline{\mathrm{Z}}_{1}+\overline{\mathrm{Z}}_{2}}{2}
$$

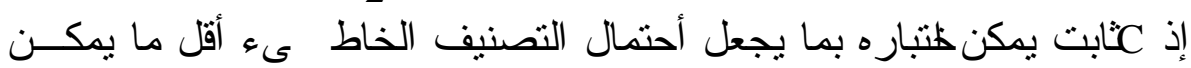
ومما تجدر الا شارة اليه ان في الامكان عرض الداره الدالة المميزة عن طريق اســتخدام

$$
\mathrm{Z}=\mathrm{X}^{\prime} \mathrm{a}
$$
المصفوفات وكما يأني (Hand,1981, 172):

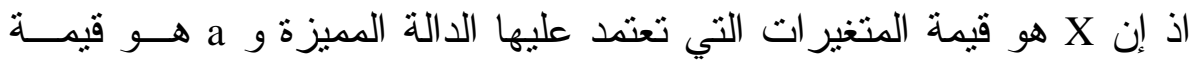

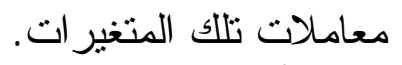

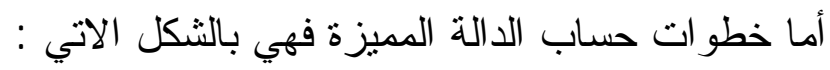

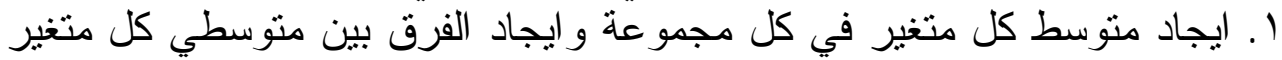

$$
\text { كما يأتي) }
$$

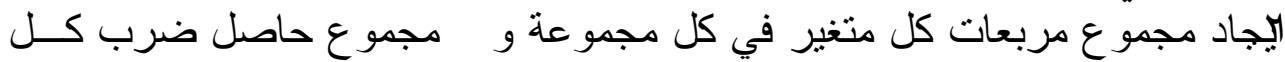

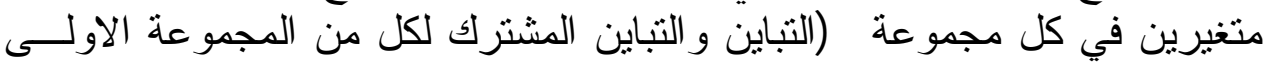

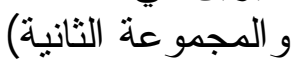
r. استخدام مصفوفة التباين و التباين المشترك المدمجة باستخدام العلاقة: 


$$
\mathrm{S}=\frac{\left(\mathrm{n}_{1}-1\right) \mathrm{s}_{1}+\left(\mathrm{n}_{2}-1\right) \mathrm{s}_{2}}{\mathrm{n}_{1}+\mathrm{n}_{2}-2}
$$

ك. استخر اج معكوس المصفوفة S.

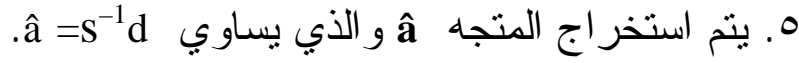
7 ـ تكوين الدالة التمبيزية بمعاملاتها بالثكل الاتيه $\mathrm{Z}=\mathrm{a}_{1} \mathrm{X}_{1}+\mathrm{a}_{2} \mathrm{X}_{2}+\ldots+\mathrm{a}_{\mathrm{k}} \mathrm{X}_{\mathrm{k}}$

$$
\text { و }
$$

V. يتم اختيار معنوية الدالة المميزة، وذلك باستخدام T2 Statistic الذي يمثل اختبار

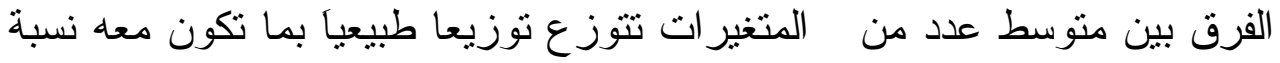

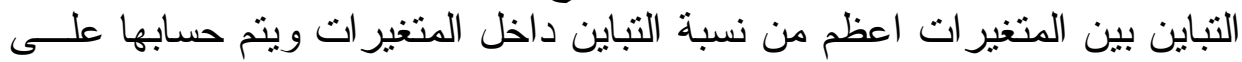

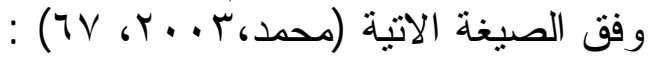

$$
\mathrm{T}^{2}=\frac{\mathrm{n}_{1} \mathrm{n}_{2}}{\mathrm{n}_{1}+\mathrm{n}_{2}} \mathrm{D}^{2}
$$

$$
\mathrm{D}^{2}=\left(\mathrm{x}^{(1)}-\mathrm{x}^{(2)}\right)^{\prime} \mathrm{S}^{-1}\left(\overline{\mathrm{x}}^{(1)}-\overline{\mathrm{x}}^{(2)}\right)
$$

$$
\text { وباستخدام صيخة مربع المسافة ....... }
$$

$$
\mathrm{F}={\frac{\mathrm{n}_{1}+\mathrm{n}_{2}-\mathrm{k}-1}{\left(\mathrm{n}_{1}+\mathrm{n}_{2}-2\right) \mathrm{k}}}^{\mathrm{T}^{2}}
$$

(k,n وان K تمنتل عدد المتغير ات

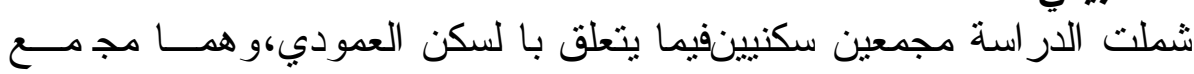

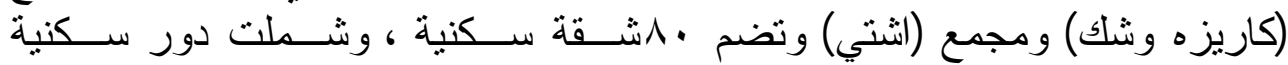

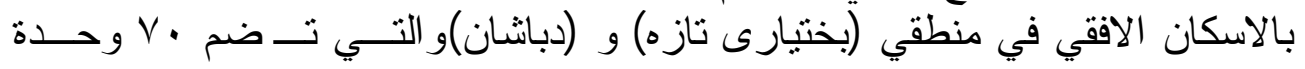

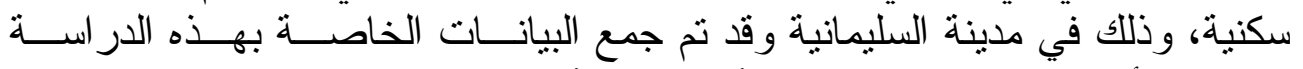

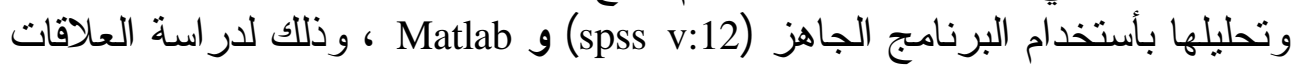

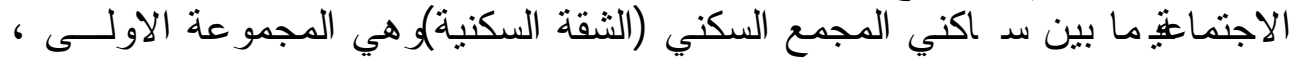


و الاسكان الافقي المتمنلة بالمجموء ة الثانية، وتــاثير العلاقــات الاجتماعيـة بــين

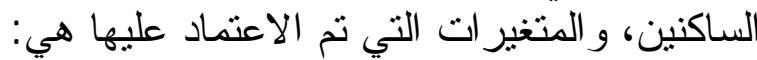
I. عدد افر اد العائلة

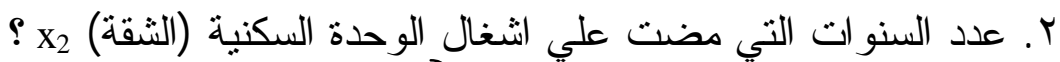

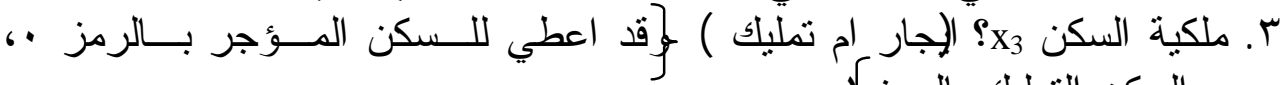

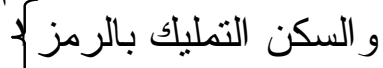

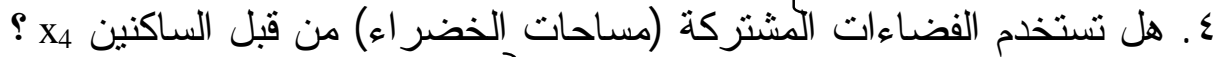

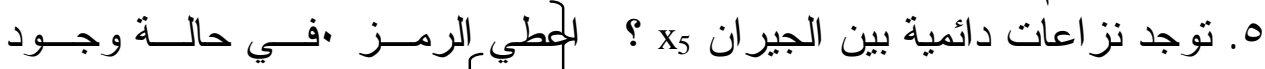

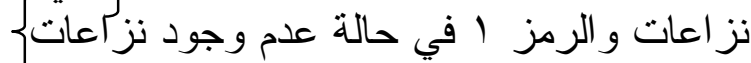

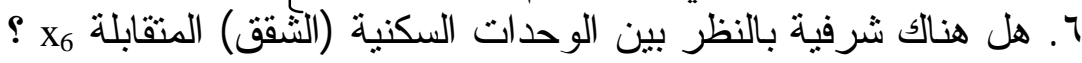

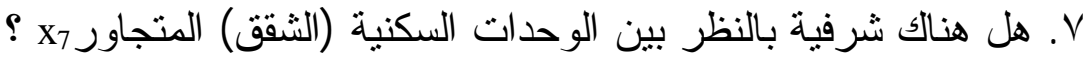

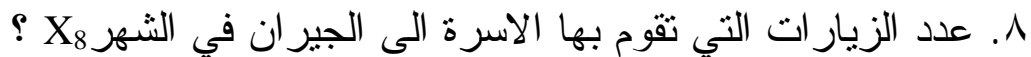

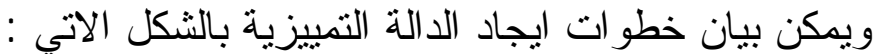

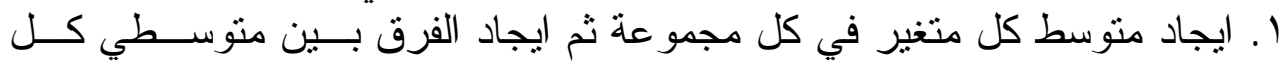

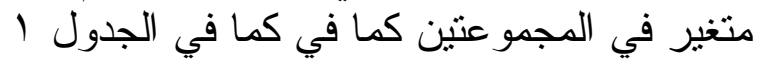

\begin{tabular}{|c|c|c|}
\hline \multicolumn{3}{|c|}{ 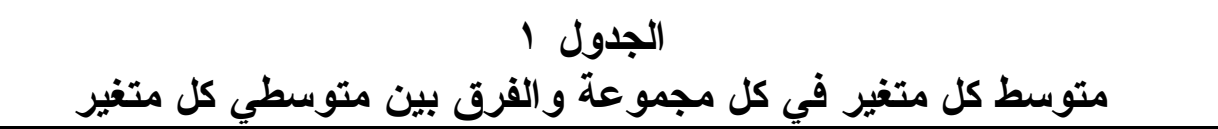 } \\
\hline متوسط متغيرات المجموعة & متوسط متغيرات المجموعة & 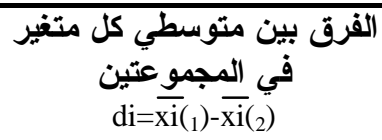 \\
\hline $\begin{array}{l}X 1(1)=5.0500 \\
X 2(1)=6.1675 \\
X 3(1)=0.4875 \\
X 4(1)=0.6750 \\
X 5(1) 0.8500 \\
X 6(1)=0.2375 \\
X 7(1)=0.5625 \\
X 8(1)=2.4000\end{array}$ & $\begin{array}{l}X 1(2)=2.15183 \\
X 2(2)=6.41795 \\
\text { X3(2) }=0.50300 \\
X 4(2)=0.47133 \\
\text { X5(2) }=0.35932 \\
X 6(2)=0.42824 \\
X 7(2)=0.49921 \\
X 8(2)=3.38874\end{array}$ & $\begin{aligned} \mathrm{d} 1 & =2.89817 \\
\mathrm{~d} 2 & =-0.25045 \\
\mathrm{~d} 3 & =-0.0155 \\
\mathrm{~d} 4 & =0.20367 \\
\mathrm{~d} 5 & =0.49068 \\
\mathrm{~d} 6 & =-0.19074 \\
\mathrm{~d} 7 & =0.06329 \\
\mathrm{~d} 8 & =-0.98874\end{aligned}$ \\
\hline
\end{tabular}

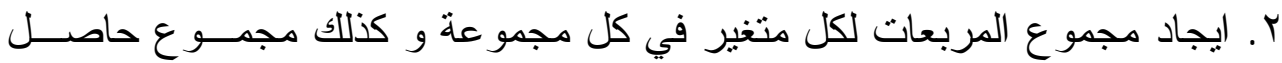

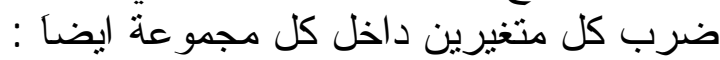

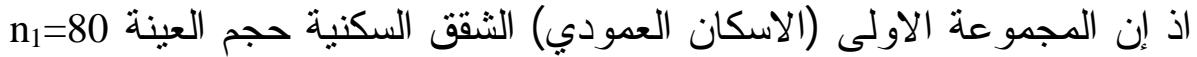

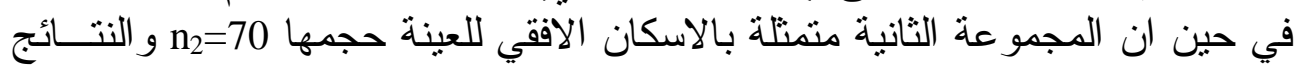

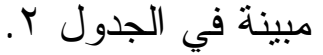




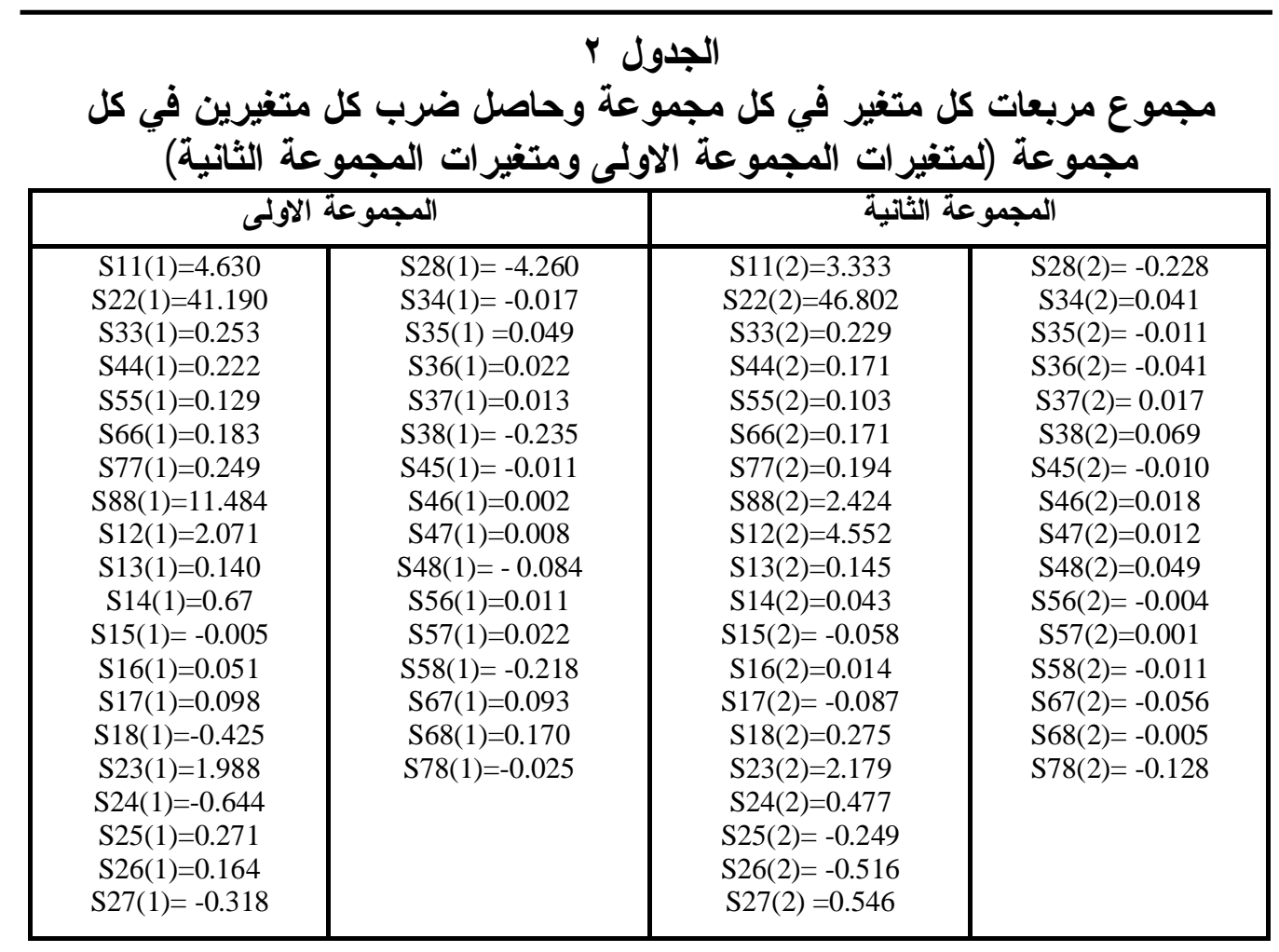

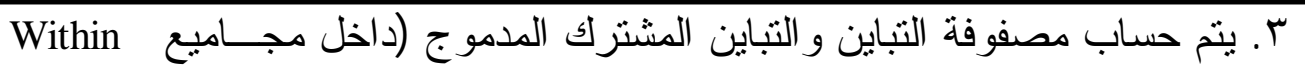
Pooled Variance-Coveriance (Group

$$
\begin{aligned}
& \mathrm{S}=\frac{\left(\mathrm{n}_{1}-1\right) \mathrm{s} 1+\left(\mathrm{n}_{2}-1\right) \mathrm{s} 2}{\mathrm{n}_{1}+\mathrm{n}_{2}-2} \\
& \text { وكما مبين في مصفوفة التباين و التباين المشترك في الجدول س }
\end{aligned}
$$

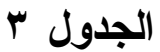

مصفوفة التباين والتباين المشترك المدموج

\section{(Poold Varianca -Coverianca Matrix)}

$\left[\begin{array}{cccccccc}4.026 & 3.228 & 0.142 & 0.056 & -0.030 & 0.034 & 0.012 & -0.099 \\ 3.228 & 43.806 & 2.077 & -0.121 & 0.029 & -0.153 & 0.085 & -2.380 \\ 0.142 & 2.077 & 0.242 & 0.010 & 0.021 & 0.008 & 0.015 & -0.093 \\ 0.056 & -0.121 & 0.10 & 0.198 & -0.011 & 0.009 & 0.010 & -0.022 \\ -0.030 & 0.029 & 0.021 & -0.011 & 0.117 & 0.004 & 0.012 & -0.121 \\ 0.034 & -0.153 & -0.008 & 0.009 & 0.004 & 0.178 & 0.023 & 0.088 \\ 0.012 & 0.085 & 0.015 & 0.10 & 0.012 & 0.23 & 0.223 & -0.073 \\ -0.099 & -2.380 & -0.093 & -0.022 & -0.121 & 0.088 & -0.073 & 7.260\end{array}\right]$

ع. ايجاد معكوس المصفوفة S وهو (S (S),وكما موضح في الجدول ؟ 


\begin{tabular}{|c|c|c|c|c|c|c|c|c|}
\hline \multicolumn{9}{|c|}{ الجدول ع } \\
\hline & 0.2668 & -0.0212 & 0.0210 & -0.0831 & 0.0630 & -0.0665 & -0.0010 & -0.0015 \\
\hline & -0.0216 & 0.0416 & -0.3469 & 0.0512 & 0.0593 & 0.0467 & 0.0014 & 0.0095 \\
\hline & 0.0285 & -0.3494 & 7.2309 & -0.6268 & -1.2644 & -0.5226 & -0.2179 & -0.0404 \\
\hline & -0.0839 & 0.0527 & -0.6526 & 5.1970 & 0.6340 & -0.1762 & -0.2095 & 0.0341 \\
\hline & 0.0615 & 0.0612 & -1.2941 & 0.6320 & 9.0449 & -0.1629 & -0.3871 & 0.1551 \\
\hline & -0.0644 & 0.0146 & 0.1462 & -0.2360 & -0.2819 & 5.7702 & -0.6061 & -0.0757 \\
\hline & -0.0015 & 0.0049 & -0.2875 & -0.2042 & -0.3758 & -0.5809 & 4.6057 & 0.0444 \\
\hline & -0.015 & 0.0099 & -0.0490 & 0.0347 & 0.1564 & -0.0713 & 0.0442 & 0.1444 \\
\hline
\end{tabular}

○. إن دالة التمييز Z هي توليفة خطية من المتغير ات وكما يأتي : $Z=a_{1} x_{1}+a_{2} x_{2}+a_{3} x_{3}+a_{4} x_{4}+a_{5} x_{5}+a_{6} x_{6}+a_{7} x_{7}+a_{8} x_{8}$

7 7. وبعد ايجاد المعكوس S وضربها في d نحصل على قيم ai وكما يأتي $\hat{a}=\left[\begin{array}{c}0.8063 \\ -0.04634 \\ -0.56422 \\ 1.10997 \\ 4.90975 \\ -1.44305 \\ 0.13131 \\ -0.04865\end{array}\right]$ وعليه فأن قيم â هي :

$\mathrm{Z}=0.8063 \mathrm{x}_{1}-0.04634 \mathrm{x}_{2}-0.56422 \mathrm{x}_{3}+1.10997 \mathrm{x}_{4}+4.90975 \mathrm{x}_{5}-1.44305 \mathrm{x}_{6}+0.13131 \mathrm{x}_{7}-0.04865 \mathrm{x}_{8}$ V. و لاختبار معنوية الدالة من العو ائل الساكنة في الوحدات السكنية بأستخدام صيغة

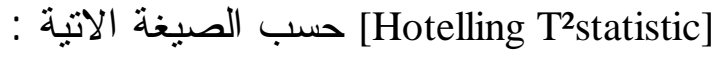

$$
\mathrm{T}^{2}=\frac{\mathrm{n}_{1} \mathrm{n}_{2}}{\mathrm{n}_{1}+\mathrm{n}_{2}} \quad \mathrm{D}^{2}
$$




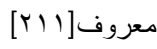
استخدام التحليل التمبزي لبيان تأثير العلاقات الاجتماعية.

$$
\mathrm{F}=\frac{\mathrm{n}_{1}+\mathrm{n}_{2}-\mathrm{k}-1}{\left(\mathrm{n}_{1}+\mathrm{n}_{2}-2\right) \mathrm{k}} \quad \mathrm{T}^{2}
$$

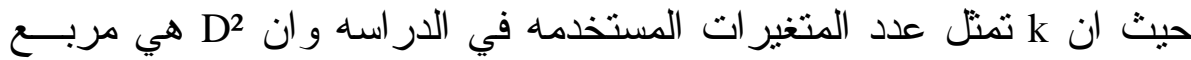

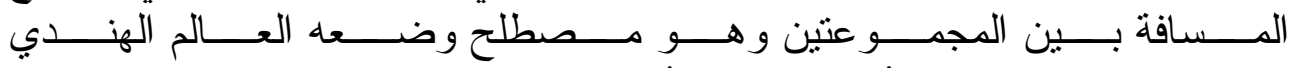
المشهور [Mahalanobis] (Overall,1972) و ويحسب كما ياتي :

$$
\mathrm{D}^{2}=\mathrm{d}^{\prime} \mathrm{a}
$$

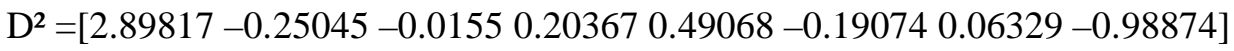

$\mathrm{D}^{2}=5.32395$

$$
\begin{gathered}
0.8063 \\
-0.04634 \\
-0.56422 \\
1.10997 \\
4.90975 \\
-1.44305 \\
0.13131 \\
-0.04865
\end{gathered}
$$

$\mathrm{T}^{2}=198.7606$

$\mathrm{F}=23.669$

وبما أن قيمة F المحسوبة (اكبر) من قيمة F الجدولية عند مسستوى معنويــة

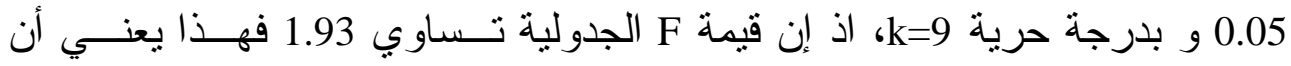

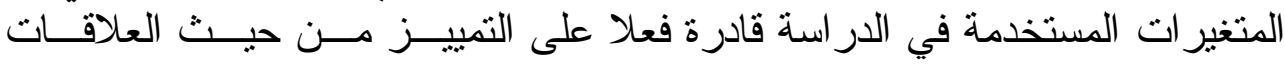

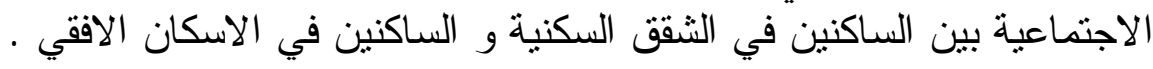

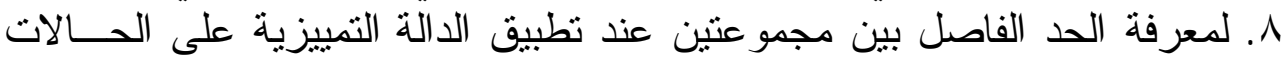

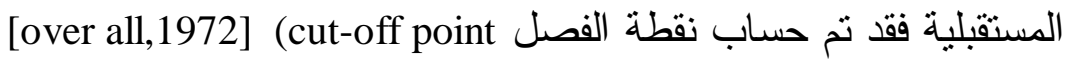

$$
\mathrm{C}=\frac{\overline{\mathrm{Z}}_{1}+\overline{\mathrm{Z}}_{2}}{2}
$$

اذ إن $\bar{Z}_{1}$ يمثل متوسط المجموعة الاولى و يمنل متوسط المجمو عة الثانية.

$$
\begin{aligned}
\overline{\mathrm{Z}}\left({ }_{1}\right)= & \hat{\mathrm{a}}_{1} \mathrm{x}_{1}\left({ }_{1}\right)+\hat{\mathrm{a}}_{2} \mathrm{x}_{2}\left({ }_{1}\right)+\overline{\mathrm{a}}_{3} \mathrm{x}_{3}\left({ }_{1}\right)+\overline{\mathrm{a}}_{4} \mathrm{x}_{4}\left({ }_{1}\right)+\widehat{\mathrm{a}}_{5} \mathrm{x}_{5}\left({ }_{1}\right)+\overrightarrow{\mathrm{a}}_{6} \mathrm{x}_{6}\left({ }_{1}\right)+\hat{\mathrm{a}} 7 \mathrm{x} 7(1 \overline{)}+\hat{\mathrm{a}} 8 \mathrm{x} 8(1) \\
\mathrm{Z} \overline{(1})= & 0.8063(5.0500)-0.04634(6.1675)- \\
& 0.56422(0.4875)+1.10997(0.6750)+4.90975(0.8500)-1.44305(0.2375) \\
& +0.13131(0.5625)-0.04865(2.4000)=8.0478
\end{aligned}
$$


$\overline{\mathrm{Z}}(2)=\hat{\mathrm{a}} 1 \overline{\mathrm{x}} 1(2)+\hat{\mathrm{a}} 2 \overline{\mathrm{x}} 2(2)+\hat{\mathrm{a}} 3 \overline{\mathrm{x}} 3(2)+\hat{\mathrm{a}} \overline{4 \mathrm{x}} 4(2)+\hat{\mathrm{a}} 5 \overline{\mathrm{x}} 5(2)+\hat{\mathrm{a}} 6 \overline{\mathrm{x}} 6(2)+\hat{a} 7 \overline{\mathrm{x}} 7(2)+$ $\hat{\mathrm{a}} 8 \mathrm{x} 8(2)$

$\overline{\mathrm{Z}}(2)=0.8063(2.15183)-0.04634(6.41795)-$

$0.56422(0.50300)+1.10997(0.47133)+4.90975(0.35932)-$

$1.44305(0.42824)+0.13131(0.49921)-0.04865(3.38874)=2.7238$

$$
\mathrm{C}=\frac{\mathrm{Z}_{1}^{-}+\mathrm{Z}_{2}^{-}}{2}=5.3858
$$

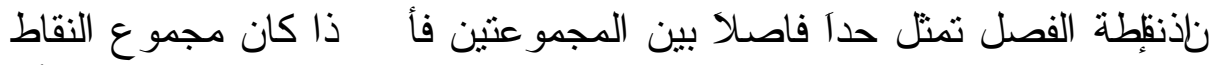

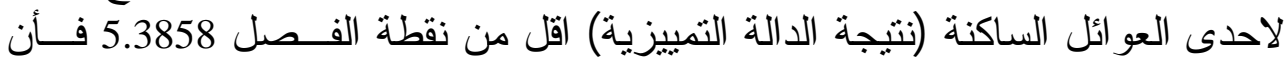

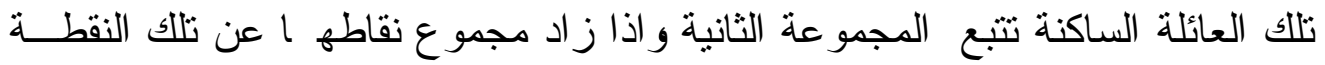

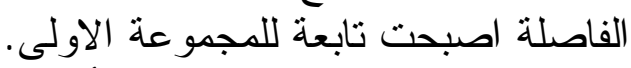

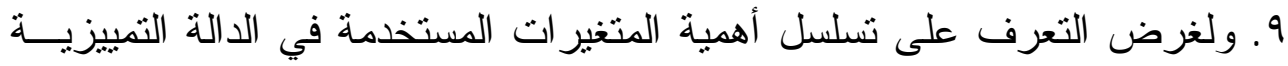

$$
\mathrm{ai}^{*}=\mathrm{ai} \sqrt{\mathrm{sii}}
$$$$
\text { ويكون ذلك بنطبيق القانون الاتي : }
$$

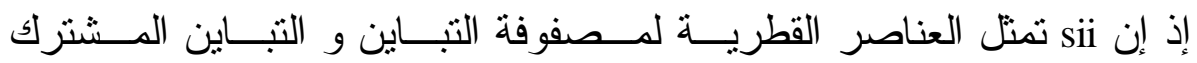

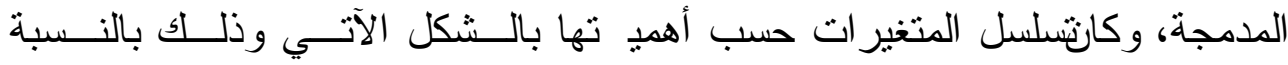

$\mathrm{a} 5^{*}=1.6793, \mathrm{a} 1^{*}=1.6178, \mathrm{a} 6^{*}=-0.6088, \mathrm{a} 4^{*}=0.4939$, للمجمو عتين $\mathrm{a} 2^{*}=-0.3067, \mathrm{a} 3^{*}=-0.2775, \mathrm{a} 8^{*}=-0.1310, \mathrm{a} 7^{*}=0.0620$

وقد تم التوصل الى توضيح تسلسل تللك المتغير ات حسـسب اهميتهــا و علــى

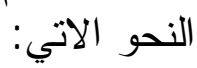
- إن متغير وجود النز اعات الدائمية بين الساكنين X5 يأخذ الموقع الاول من حيــــ

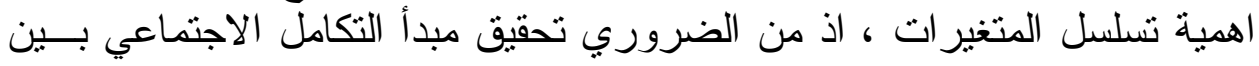

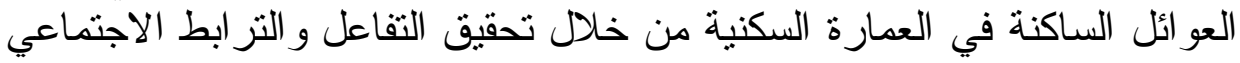

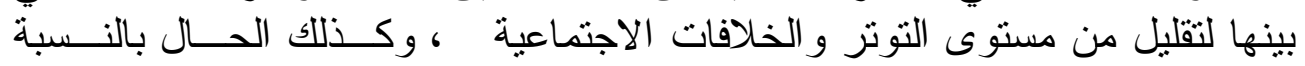

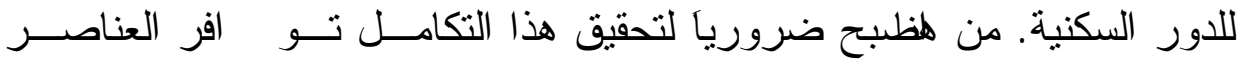

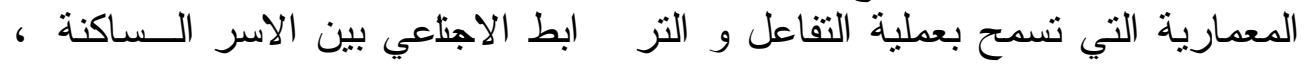

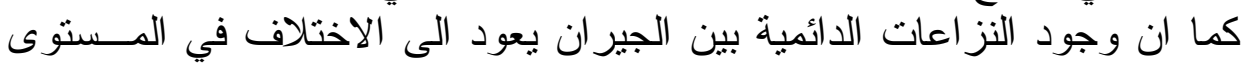

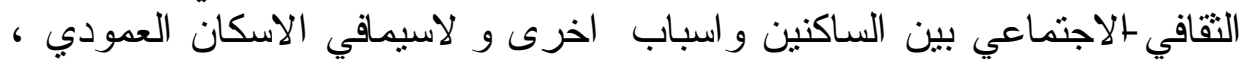

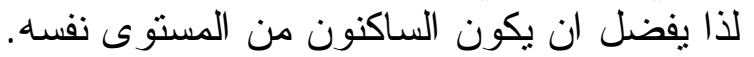
وجاء متغير عدد افر اد العائلة

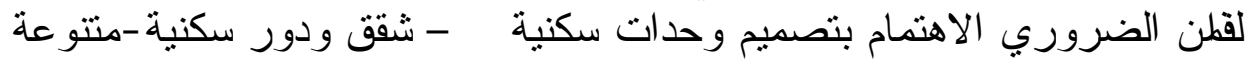

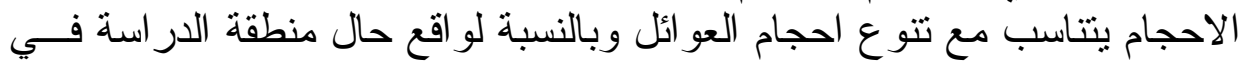

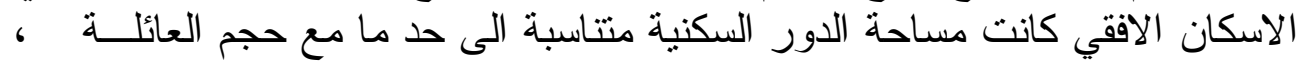

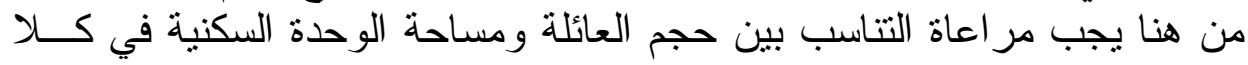
النوعين من الاسكان الافقي و العمودي. 


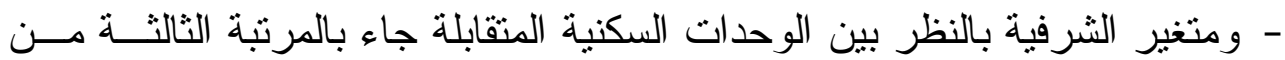

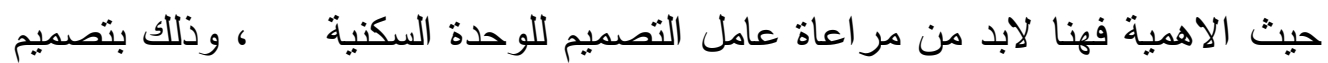

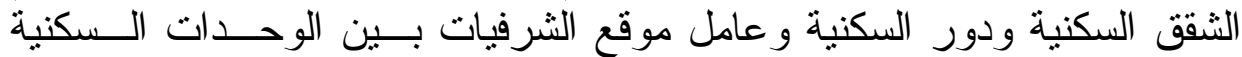

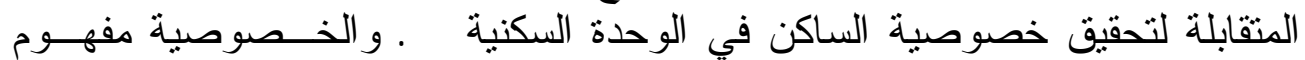

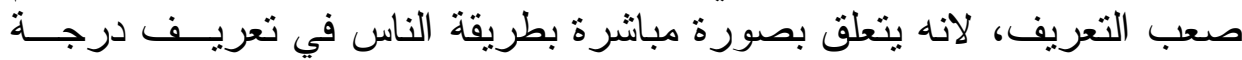

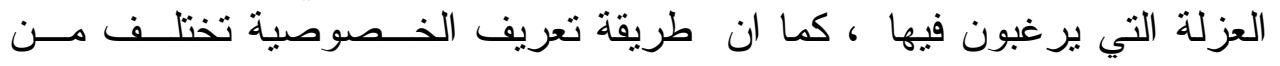

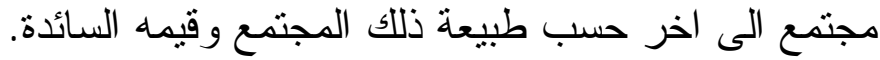

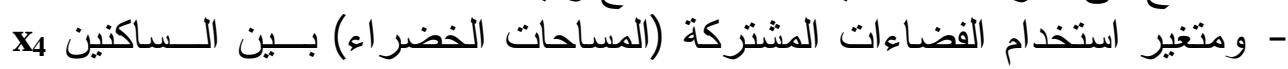

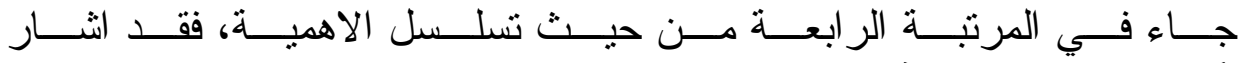
(W.Michelson,1970)

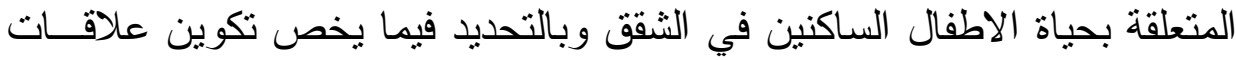

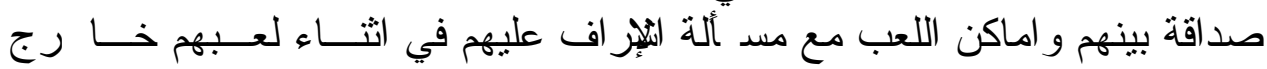

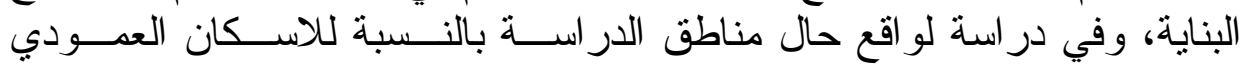

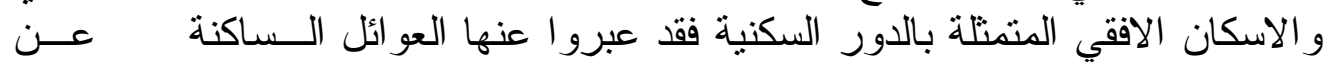

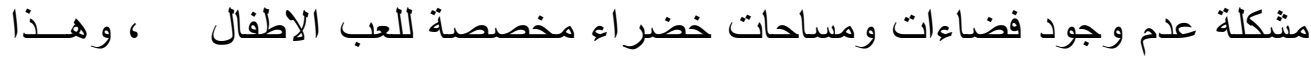

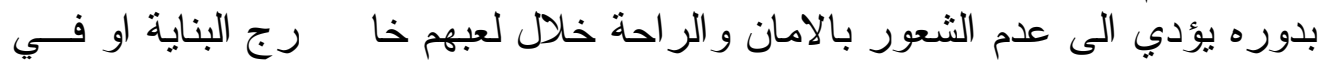

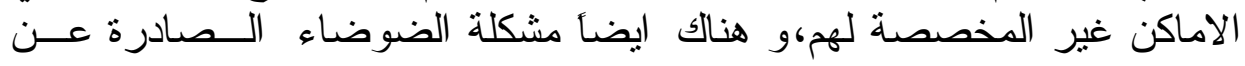

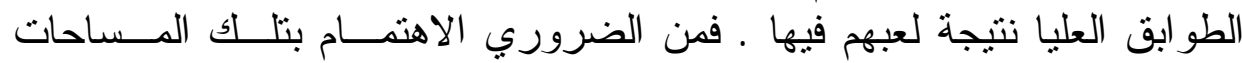

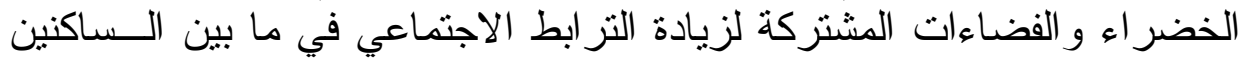

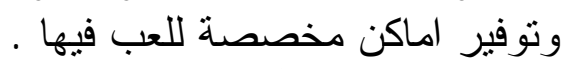

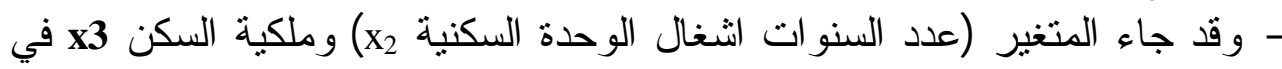

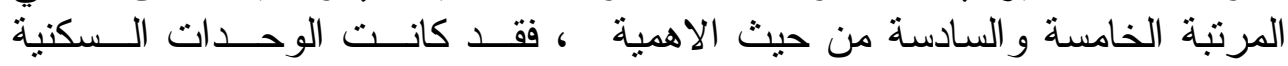

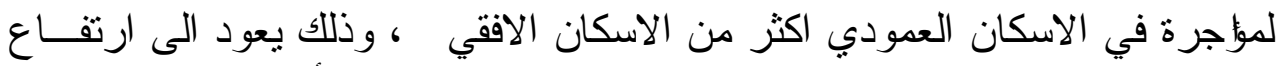

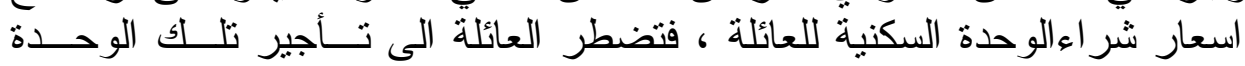
- وبالنسبة لمتغير عدد الزيار ات التي تقوم بها الاسرة الى الجيران x8 أخذ الموقع

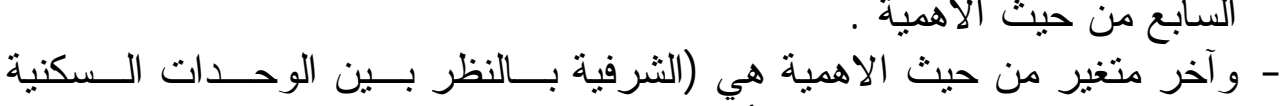

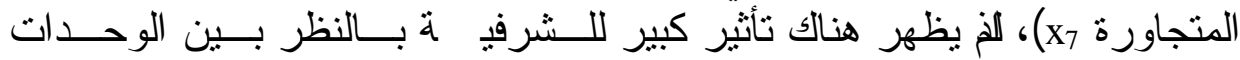

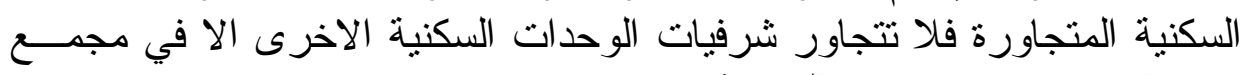

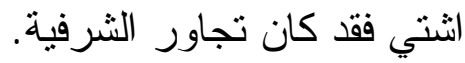

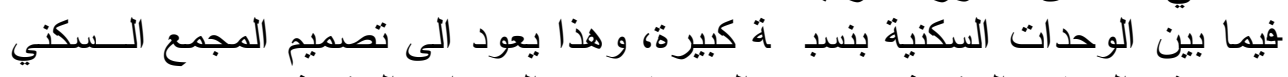
وموقع العمارة السكنية وتصميم الثرفيات في الوحدات السكنية. 


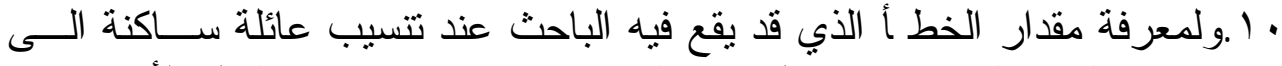

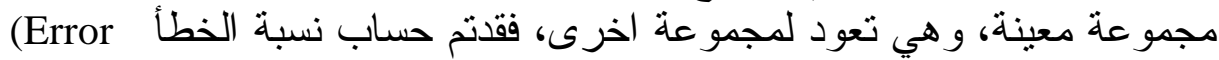
$\mathrm{p} 1=\mathrm{p} 2=\mathrm{f}\left(-\sqrt{\mathrm{D}^{2} / 2}\right)=\mathrm{f}(-1.15)$

ومن جدول نسب المساحات التوزيع الطبيعي القياسي وجد الباحث ان : p1=p2=1-0.8749=0.125

الاستتنتاجات

ا ـ من خلال الدالة التمبيزية التي تم التوصل اليها في منن البحث يستطيع الباحث

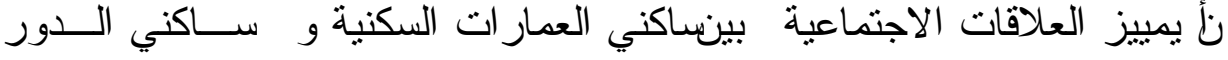
السكنية .

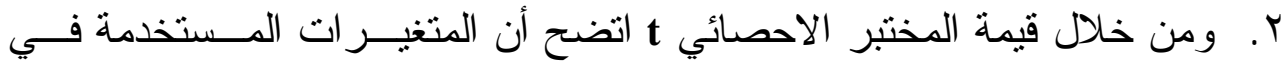

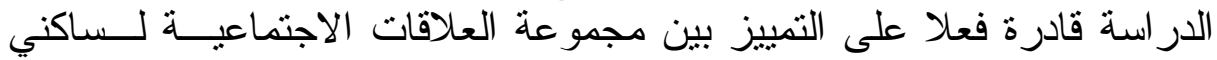
شقق وبين العلاقات الاجنماعية لساكني الدور السئ السكنية.

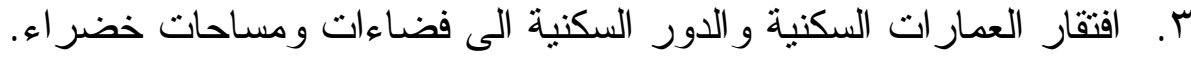

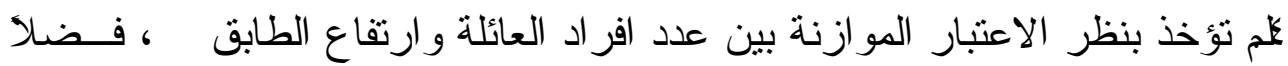
عن حجم العائلة ومساحة الوحدة السكنية.

التوصيات

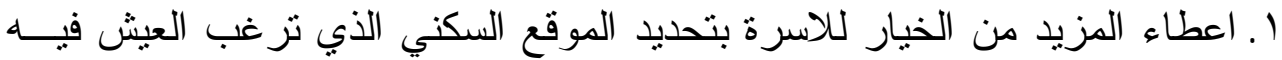

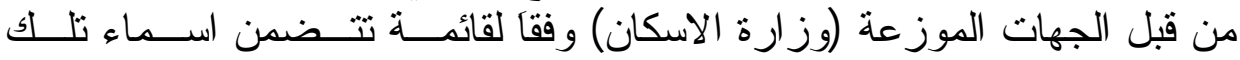

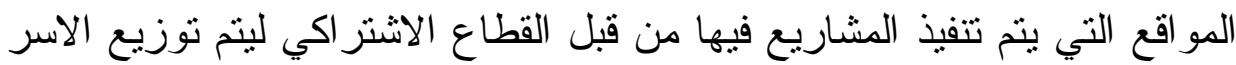
عليها حسب الاولوية و الحاجة.

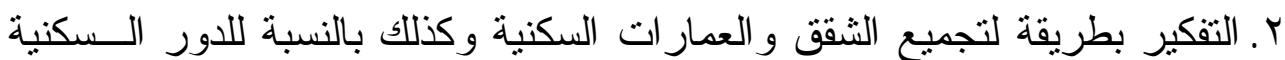

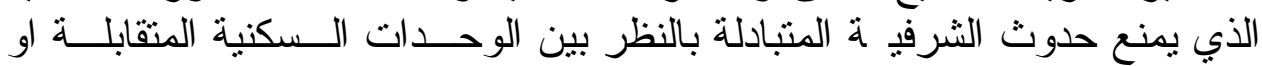
المتجاورة لاعتبار ات اجتماعية و اخلاقية.

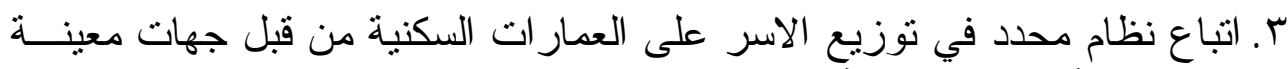

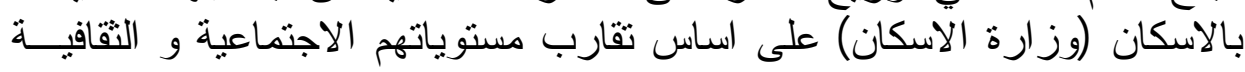

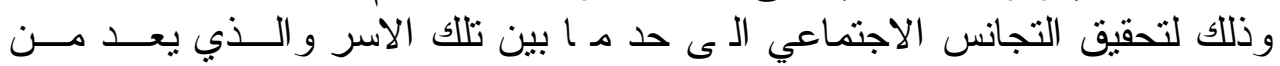

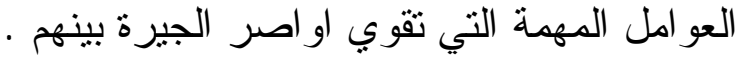

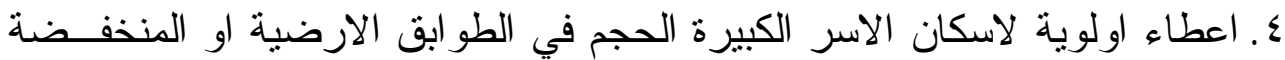
من المباني السكنية.

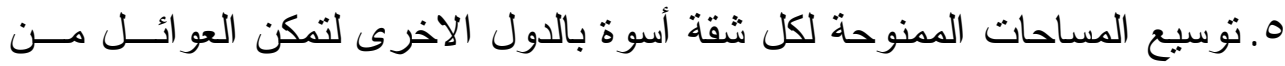

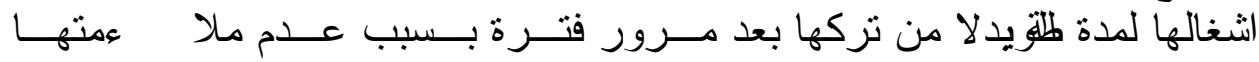
للمتغير ات المسقبلية. 


\section{أولاًا - المر اجع باللغة العربية}

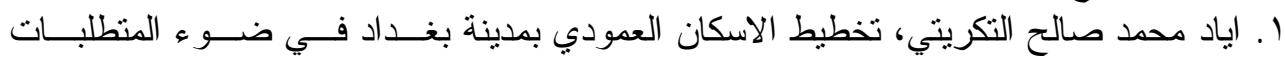

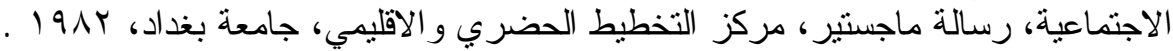

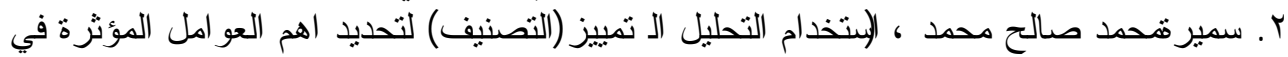

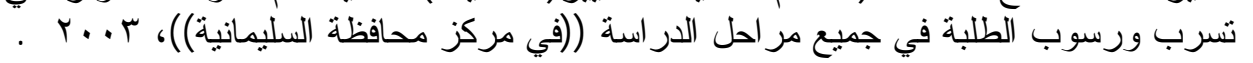

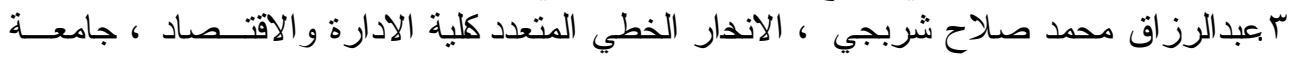

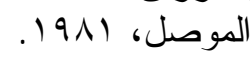

ع .فارس غانم احمد ، در اسة احصائية تميزية تسوس الاسنان لاى الاطفال، مجلة تتمية الر افـدين

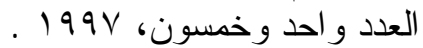

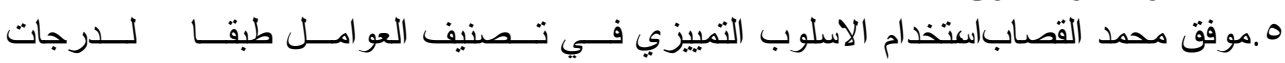

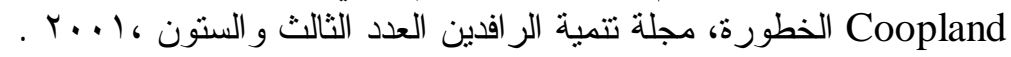

\section{ثانياً - المر اجع باللغة الاجنبية}

1. Afifi,A.A .Azen,S.P., Statistical Analysis Acompwte Orieanted Approach.Academic Presses, Newyork,London, 1972.

2. Anderson T.W., (An introduction to Multivariate Statistical Analysis), $2^{\text {nd }}$ Edition, John Wiley and Sons, 1984 .

3. Comphell, Norma, (Shtrunken Estimator Indiscriminate and Canonical Variate Analysis), Applied Statis Ties ,N.I.vol $29,1980$.

4. Giri, N.C, (Multivariate Statistical Inference) A Cademic Press, Newyork, Sanfrancisco, London, 1977.

5. Hand,D.J.,(Discrimination and Classification) Wiley Series Inprobability and Mathematical Statistic, 198111-Stevens، J, (Applied Multivariate Statistic for the Social Sciences , $4^{\text {th }}$ Edition, Mahwah, Newgersey, London-USA.2002 .

6. Overall .E.J., (Applied Multivariate Analysis) Newyork- Mc.Graw-Hill, 1972.

7. W. Michelson, Man and his Urban Environment, Mc.Graw-Hill ,1970 . 


\section{إعــــان}

يصدر قريباً عن مجلة تتمية الر افدين في جامعة

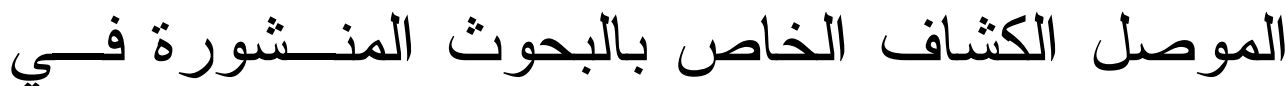

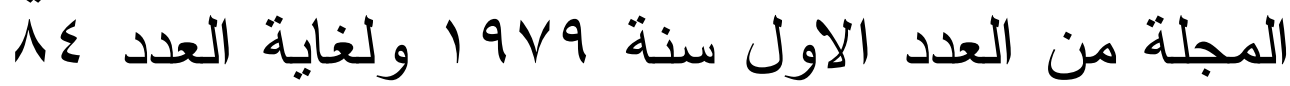

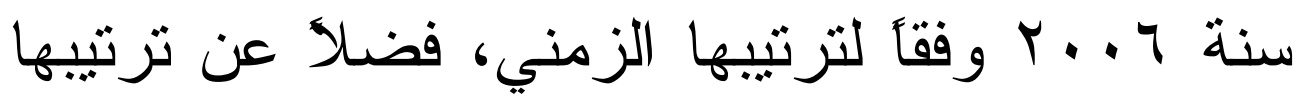
الابجدي لاسماء السادة الباحثين.

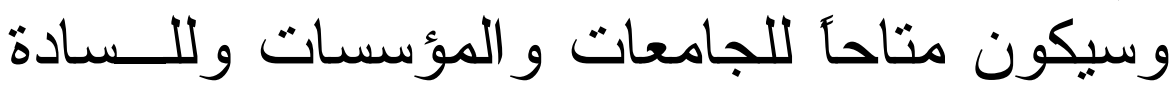
الر اغبين بالاقتناء مر اسلة المجلة.

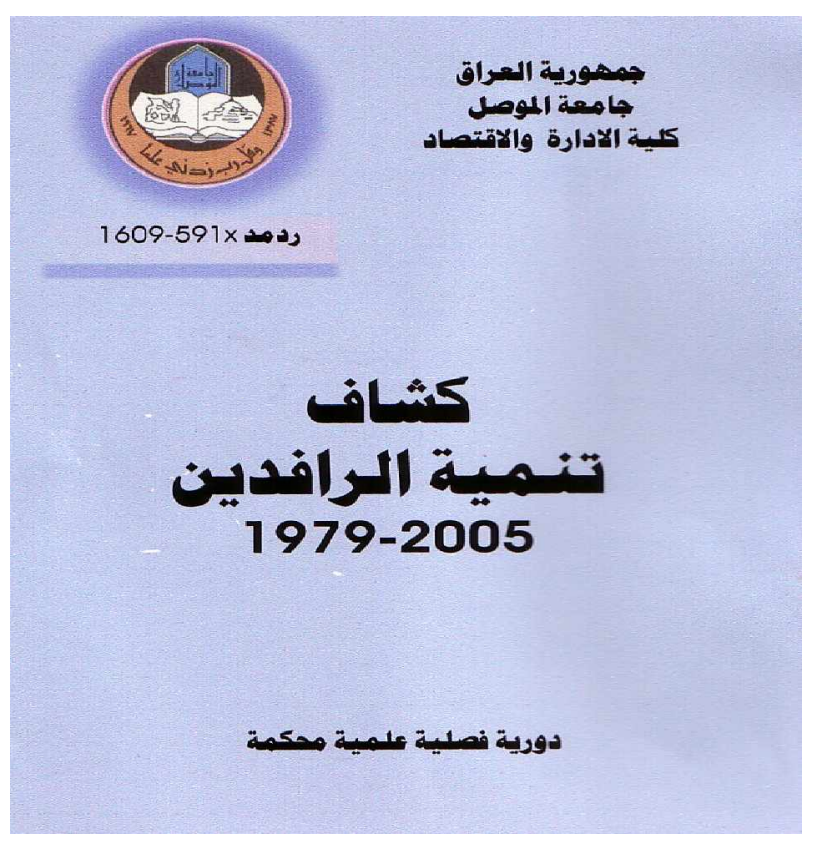

